\title{
INTERACCIONES ENTRE ESPAÑOLES DE CHILOÉ Y CHONOS EN LOS SIGLOS XVII Y XVIII: PEDRO Y FRANCISCO DELCO, IGNACIO Y CRISTÓBAL TALCAPILLÁN Y MARTÍN OLLETA
}

\author{
INTERACTIONS BETWEEN SPANIARDS OF CHILOÉ AND CHONOS \\ IN THE XVII AND XVIII CENTURIES: PEDRO AND FRANCISCO DELCO, \\ IGNACIO AND CRISTÓBAL TALCAPILLÁN AND MARTÍN OLLETA
}

\author{
Ximena Urbina Carrasco ${ }^{1}$
}

\begin{abstract}
Se presentan cinco casos en que las fuentes coloniales dan cuenta de individuos del grupo étnico-cultural chono, de las costas de la Patagonia Occidental, que en los siglos XVII y XVIII tuvieron contacto con las autoridades políticas y misionales de la provincia de Chiloé, la más meridional del reino de Chile. Requerida su información por los españoles, los llamados "caciques chonos" dieron noticias del mundo austral al que pertenecían, en el que España nunca tuvo presencia efectiva, pero su jurisdicción y control correspondía a Chiloé. Sus informaciones fueron dando lugar a la formación de un conocimiento geográfico y cultural español del territorio entre el archipiélago de las Guaitecas y el confín del continente, que valoraron con interés geopolítico. Siendo este, el geopolítico, el principal interés en ese mundo bordemarino, las informaciones requeridas y proporcionadas sobre colonias de náufragos españoles, de ingleses ocultos, o de indígenas aun no conocidos, fueron determinantes y movilizaron o no a los colonos de Chiloé sobre su frontera austral.
\end{abstract}

Palabras claves: chonos, período colonial, interacción, Chiloé, Patagonia.

This study presents five cases in which colonial sources discuss individuals from the Chono ethnic-cultural group from the coast of Western Patagonia. In the XVII and XVIII centuries, these individuals came into contact with political authorities and missionaries in the province of Chiloé, the most southerly in the kingdom of Chile. When required by the Spanish, the so-called Chono "caciques" gave news of their southern world, where Spain never maintained a real presence, despite having jurisdiction and control over Chiloé. The information delivered by these Chono caciques provided the Spanish with geographical and cultural knowledge of the territory between the Guaitecas archipelago and the continental border, which they considered to be of geopolitical significance. As this geopolitical element was the main interest in this coastal world, the information required and provided about colonies of Spanish shipwreck survivors, of hiding Englishmen, or of unknown indigenous groups, was decisive in whether or not the Chiloé colonists decided to move beyond their southern border.

Key words: Chonos, the colonial period, interaction, Chiloé, Patagonia.

\section{La Frontera Sur de Chiloé Colonial}

Durante el período colonial no hubo ciudad ni fuerte español permanente al sur de la isla grande de Chiloé. Todo el territorio que media entre esa isla y el confín del continente pertenecía jurídicamente a la provincia de Chiloé (Vázquez de Acuña 1993), cuya única ciudad era Castro, fundada en 1567. Aunque eran tierras que le pertenecían de derecho, de hecho no fueron ocupadas porque no presentaban los atractivos económicos que en otras latitudes americanas movilizaron rápidamente a los españoles y les asentaron: no había oro, plata ni piedras preciosas, y la población indígena no era atractiva como para trasladarla y ocuparla en el servicio. No lo era por poco numerosa, y por ser considerada "gente de poquísima capacidad" (AA, VV. 1927:22), debido a la enorme diferencia cultural entre los españoles -con un modo de vida definido por la agricultura, la llanura y el caballo (Urbina 2014:17)- y los grupos de indígenas llamados por la historiografía "canoeros australes", mariscadores bordemarinos cuya embarcación era considerada por los hispanos como el elemento más representativo de su cultura. El rigor del clima y la ausencia de mantenimientos agrícolas fueron

1 Instituto de Historia, Pontificia Universidad Católica de Valparaíso. Paseo Valle 396, Viña del Mar, Chile. maria.urbina@ucv.cl 
otros factores para la falta de interés en fundar un establecimiento español en la Patagonia Occidental, pero más relevante fue el convencimiento de lo ineficaz que sería, porque, como lo probó la corta existencia de capillas jesuitas en el archipiélago de las Guaitecas en las décadas de 1610 y 1620; y un pequeño fuerte de madera que duró en pie 18 meses en la isla Caychilu, archipiélago de los Chonos, en 1750, cualquier campamento, fuerte o ciudad se convertiría en solo un punto invisible en la inmensidad de los archipiélagos y estuarios del mar interior patagónico.

Debido a la dificultad de acceso a los archipiélagos australes -por ser la navegación riesgosa a causa de la crudeza de los vientos y la existencia de temibles golfos-, la lejanía, la falta de interés económico en ellos y la pobreza de una provincia aislada y encerrada en sí misma para sobrevivir (Urbina 2012 [1983]), como en otros lugares de frontera, los españoles de Chiloé fueron conociendo el espacio que no ocupaban a través de expediciones de reconocimiento (Hanisch 1982). Estas fueron ejecutadas por militares de la plaza, a quienes en diferentes momentos de los siglos XVII y XVIII se les encomendó reconocer las costas buscando supuestos sobrevivientes de naufragios españoles o de las frustradas colonias del estrecho de Magallanes (1584); jesuitas tras almas que convertir; explotación material de naufragios; búsqueda de asentamientos ocultos de extranjeros; y, a fines del siglo XVIII, de conocimiento hidrográfico (Urbina 2013). Estas expediciones no pasan de 15 durante ambos siglos, y casi todas ellas fueron originadas por las informaciones sobre náufragos, sobrevivientes, extranjeros y gentiles (indígenas aún sin evangelizar) que en distintos momentos dieron los habitantes originarios de las costas al sur de Chiloé, y que por su valor para los intereses locales de esa provincia, o para los intereses imperiales de la corona de España, no pudieron dejar indiferente a las autoridades.

Con las noticias de indígenas y las expediciones de navegantes españoles se fue generando un corpus de conocimiento sobre aquellas tierras ignotas. Las fuentes escritas llegadas hasta nosotros permiten individualizar a cinco personas que, en distintas épocas y sin ser apremiados (al menos no directamente), se acercaron a los españoles de Chiloé, y preguntados o no por estos, dieron información sobre grupos -indígenas y no indígenasque poblaban las tierras del sur. Estos, llamados caciques por los españoles, e identificados como chonos, son personajes interesantes por ser las llaves con las que se abrió la Patagonia Occidental a un conocimiento geográfico imaginario (cuando contaban), y también a un conocimiento geográfico real o empírico (cuando eran guías). Ofrecemos este circunscrito estudio como un caso de frontera interétnica hispanoamericana colonial, una de "alteridad radical", como diría Todorov (1987), que contribuye a conocer, desde la disciplina histórica, el cómo se van construyendo las representaciones que los grupos humanos hacen y han hecho en el pasado del mundo físico y cultural que les rodea, creando con ello otra realidad (Chartier 1992).

En cuanto al concepto "cacique", como es sabido, la apreciación hispana respecto del liderazgo indígena no tiene por qué ser coincidente con la posiblemente existente en la realidad. El reconocimiento español de la categoría de caciques era una manera de ordenar mentalmente el territorio indígena y designar a interlocutores oficiales, y como a tales los entendemos en este artículo. Con el concepto "chono" los españoles nombraban así genéricamente a "varias parcialidades esparcidas por muchas islas" (Sobrino 1631:63v). Los caciques chonos aquí retratados (únicos individualizados en los documentos coloniales) hablaban la misma lengua, aunque algunos frecuentaban (o al menos es posible vincularlos a) lugares más cercanos a Chiloé, y otros a lugares más lejanos a ella.

Ellos son representantes individualizados del complejo panorama étnico del bordemar austral al momento del contacto, distintos grupos de cazadores y recolectores marinos conocidos genéricamente como "grupos canoeros australes", tradicionalmente denominados, de norte a sur, chonos, kaweskar y yaganes o yámanas, aunque en la documentación colonial se advierten más identidades que estas tres (Álvarez 2002; García 1811). Los chonos (Reyes et al. 2015) fueron capturados, sometidos a esclavitud y evangelizados desde los comienzos de la presencia española en Chiloé (Urbina 2007), mientras que los otros grupos fueron contactados de manera sistemática en la segunda mitad del siglo XVIII y el XIX (Lira y Legoupil 2014; Mena 1985) (Figura 1).

\section{Pedro Delco, 1609-1620}

Pedro Delco -que así lo llamaron los españolesentró en contacto con Chiloé en algún momento antes de 1609 (Quiroz y Olivares 1988). El gobernador 

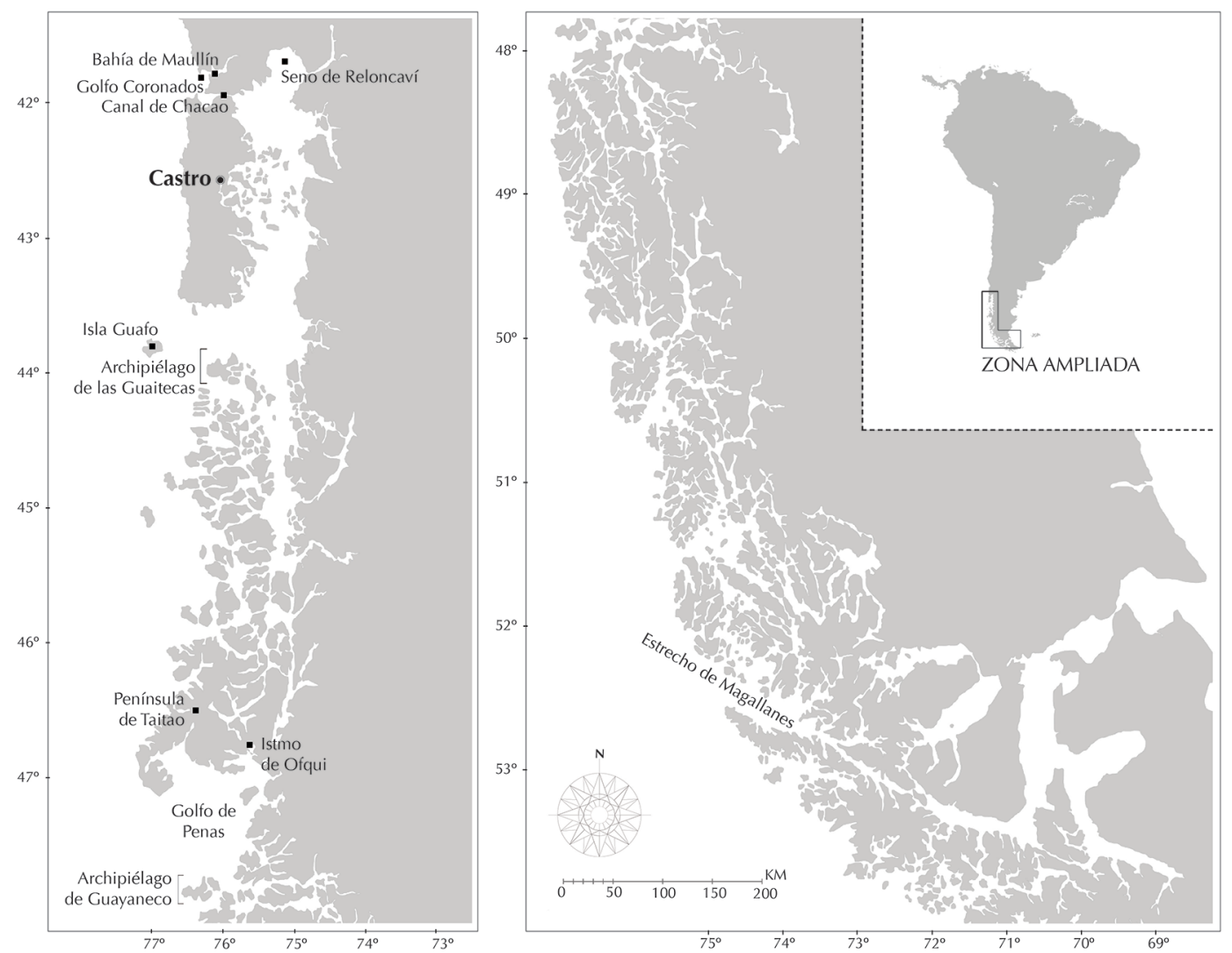

Figura 1. Mapa de los canales occidentales del Pacífico sur, entre los 41 y 54 grados de latitud sur. Elaborado por Camila Fuenzalida Polanco.

Map of the western channels of the South Pacific, between 41 and 54 degrees south latitude. Prepared by Camila Fuenzalida Polanco.

de la provincia lo consideró "cacique principal" de las "islas de los chonos y huilles", y como tal lo reconoció como "cabo y gobernador de ellas". Por "haber tenido mucho trato con los de la isla grande", ya había sido bautizado y hablaba bien el mapudungun o lengua mapuche cuando en 1609 llegó "a negociar sus negocios" a algún lugar de Chiloé donde los jesuitas estaban en misión, liderando a un grupo de personas en cinco dalcas (AA.VV. 1927:110-111). Probablemente el interés hacia Chiloé, por parte de los chonos que recorrían las islas Guaitecas, es fruto de los contactos prehispánicos con su población originaria. Luego, los españoles los capturaron en razzias para venderlos como esclavos, como lo hacían en otras regiones de América en las que presionaban en los bordes de la tierra efectivamente colonizada, para mantener a raya a los externos y proteger la seguridad del interior. Los españoles se instalaron en Chiloé desde 1567 y hacia 1609 podemos suponer que, además de las capturas (que no se pueden cuantificar), otros caciques o "parcialidades" mantenían comercio con ellos, ofreciéndoles la única mercancía que en sus islas podía interesarles: "piezas" (esclavos), y por ello, tenían relaciones pacíficas. Con la intención de mantener comunicación, los jesuitas dieron a Delco y a sus acompañantes algunos objetos que los chonos estimaban mucho (peines, agujas y medallas de estaño), y que habían conocido en anteriores interacciones (AA. VV. 1927:110-111).

Delco informó, en este primer encuentro, que las islas existentes al sur de Chiloé eran muchas, que todas estaban pobladas, y que "hacia el estrecho" vivía un grupo distinto a ellos, que identifica como huilles, a quienes considera "broncos y groseros". Informó que los chonos maloquean a los huilles "y se sirven de ellos, y aun los venden o dan en don a otros". Como el jesuita que escribe, Ferrufino, dice que ha visto huilles, pero para esa fecha sabemos que no había salido de Chiloé, se deduce que eran 
vendidos a Chiloé por los mismos chonos (AA. VV. 1927:110-111). Por lo tanto, además de los negocios que Delco pueda haber tenido con particulares y/o con la autoridad de Chiloé, los jesuitas vieron que él podía "darnos luz [-dicen-] de aquellas gentes y naciones". Acababan de hacerse cargo de la misión de Chiloé ese año de 1609, y el presentarse Delco y su gente, revelando grupos de gentiles desconocidos en Chiloé, significó que desde un comienzo las islas y gentes al sur fueron contempladas en los planes de evangelización.

Todo lo anterior lo sabemos por una carta de 1611. Se menciona nuevamente a Pedro Delco en otra de 1612, donde se dice que para entonces ha ido todos los años a Chiloé, y sigue entrevistándose con los jesuitas ("Adiciones a la carta anua de 1611":73). Desde 1613 hubo visitas misionales al archipiélago de los Chonos, sin que sepamos cuántas, solo que para 1618 había habido al menos dos: 1613 y 1618 ("Cartas Anuas de la provincia del Paraguay de los años 1618 y de 1619”:195), siendo mediadas por Delco como interlocutor y congregador de los chonos (AA. VV. 1927:380-384).

Un capitán español, Juan García Tao, se valió de Delco para explorar los archipiélagos australes, siendo esta ocasión la primera de muchas en que españoles navegaron buscando poblaciones de europeos aislados. García Tao, que salió de Chiloé con tres dalcas (embarcación indígena hecha de tres tablones cosidos) en 1620, hizo su primera escala en "las islas del gobernador Pedro Delco, cacique de las islas de los chonos". Allí recogió a Delco, quien estuvo dispuesto a colaborar, agregando otras dos dalcas a la expedición. La actitud de Delco con este militar español en reconocimiento geopolítico oficial fue distinta a la que tenía con los jesuitas. Mientras los religiosos iban a visitarlos sin otros acompañantes que indígenas de Chiloé, llevando objetos materiales que ellos apreciaban, y permaneciendo durante unas semanas en una o más islas Guaitecas, este capitán iba con la intención de penetrar hacia las espaldas del territorio. García Tao anota en su relación que Delco "impide mucho que no se descubra la ciudad de los españoles porque no se haga pasaje para su tierra". Por lo anterior, podemos suponer que Delco frecuentaba las Guaitecas cuando era la posible época de intercambio (verano), pero el resto del año recorría, él y su gente, "su tierra", es decir, hacia el sur. Pedro fue hostil a la expedición de García Tao: dio muerte al indígena que llevaba como guía (Millacar, "de quien me había de valer porque era guía y lengua para llevarme a Caicof, donde era el camino para ir a la ciudad"); lo abandonó al cabo de ocho jornadas hacia el sur; impidió que otros indígenas dieran información a García Tao, o instó a que la dieran errada, para provocar el fracaso de la expedición (García Tao:440-441).

\section{Francisco Delco, 1630}

Después del viaje de García Tao, que no encontró la población patagónica oculta, la documentación no menciona más a Pedro Delco. Sin embargo, muestra al cacique Francisco Delco, en 1630. Suponemos que este Francisco es distinto a Pedro, porque hay bastante tiempo de diferencia (21 años) entre la primera alusión a Pedro y la de Francisco. El cronista jesuita Diego de Rosales menciona a Francisco Delco: un cacique que fue visitado por el misionero Juan López Ruiz, y que accedió, por medio de la "mansedumbre y agrado" del padre, y de "algunos donecillos", a ser doctrinado y bautizado. No se dice cuán lejos de Chiloé era posible situar a ese cacique. Después de visitados por López, Francisco Delco y su gente "han tenido alguna comunicación con los españoles e indios cristianos de Chiloé, y han buscado alguna ropa con qué cubrir su desnudez" (Rosales 1991:223-224), lo que muestra su interés en objetos para el intercambio. Rosales agrega que el gobernador insular dispuso ir a buscar a los chonos ya cristianos y trasladarlos a Chiloé para su mejor adoctrinamiento. Se les intentó insertar en el sistema colonizador, haciéndolos trabajar, pero ellos "apellidaron libertad y se rebelaron contra los españoles", y yéndose de allí "se volvieron a hacer fuertes en sus islas" (Rosales 1991:225). Luego, López envió un mensajero a buscar a Francisco Delco para que accediera a retomar relaciones con los jesuitas y encontrarse con él en la isla Quilán (43⒉' $18^{\prime \prime}$ latitud sur y $74^{\circ} 15^{\prime} 46^{\prime \prime}$ longitud oeste), lo que de hecho ocurrió, y el jesuita le convenció de devolverse a buscar a los demás caciques chonos "para que den la paz" y todos se trasladasen a Quilán, donde serían evangelizados a distancia de los españoles. Pero a Delco, dice Rosales, solo le siguieron "algunos de sus aliados", con quienes se trasladó a la isla, reencontrándose con López. Una vez allí, a petición del jesuita, Delco insistió en requerir a otros, enviándoles un mensajero. Los argumentos que los convencieron, y que hicieron que finalmente un grupo de chonos, liderado por Francisco Delco, se acercaran a esta isla cercana a 
Chiloé fueron la protección jesuita ofrecida frente a los españoles "que habían de venir sobre ellos... con todas sus fuerzas y hacerlos esclavos" (Rosales 1991:228).

¿Dónde conoció López Ruiz a Francisco Delco? ¿Fue en sus correrías misionales salidas desde las Guaitecas, cuando allí aún existía capilla? A través de él, como había sido antes con Pedro, los jesuitas intentaron dejar "abierto el camino por los chonos para otra nación que estaba más adelante" (Rosales 1991:230). Esta “nación" a la que se refería Francisco, ¿será la misma de los "huilles” que señaló Pedro? Huilli, en mapudungun, quiere decir sur. A diferencia de Pedro y su gente, Francisco y los suyos se asentaron temporalmente en dos ocasiones (por la fuerza o atraídos por objetos materiales) cerca de la isla grande de Chiloé. En los años que median entre Pedro y Francisco, al parecer, creció el interés de los chonos por contactarse con los jesuitas y chilotes en general. Por último, la información de Francisco sobre "otra nación que estaba más adelante" incentivó el interés de los misioneros por nuevos "gentiles" a quienes convertir.

\section{Ignacio Talcapillán y la "Nueva Gente" ¿1629 o 1631?}

La primera vez que se menciona Talcapillán, al menos en un documento que haya llegado hasta nosotros, es en 1629. Es reconocido como cacique chono de un sector más al sur del que antes era Pedro Delco. Dice ese año un jesuita que Talcapillán habitaba regiones remotas que distaban 40 leguas de Castro -otro documento dice 60- (con toda la imprecisión de esta estimación, podríamos suponer las 40 leguas desde Castro en $44^{\circ}$ y medio, y las 60 en $45^{\circ}$ y medio, latitud sur), y que tiene más cantidad de vasallos que otros caciques. La historia de Talcapillán la conocemos por la carta anua correspondiente a los años 1629 y 1630 , y a la Vida del padre Juan López Ruiz, de Diego de Rosales, escrita en la década de 1670. Pero en la Vida se ve que hay dos viajes sucesivos de López Ruiz hacia el sur de Chiloé: el primero tiene como protagonista a Francisco Delco, que acabamos de exponer, y el segundo, a Ignacio Talcapillán.

Puede o no que se trate del mismo personaje, porque la carta anua citada y la información de Rosales son prácticamente iguales entre sí, y ambas lo son del relato anterior que hace Rosales de López y Francisco Delco, excepto algunos aspectos:
Talcapillán era cacique de chonos que "estaban más adelante" que los de Delco, nación que llama Rosales "de los payos"; a ellos envió López un mensajero chono, anunciándole la visita del padre, con una cruz; la isla del encuentro con Talcapillán no se llama Quilán, sino Deseada; y luego de la doctrina, que duró "muchos días", López bautizó a Talcapillán, quien escogió por nombre Ignacio (Rosales 1991:233). Después de ello, no hay más noticias del cacique Ignacio. El historiador jesuita Miguel de Olivares, que escribe cien años después, pero probablemente bien documentado, también refiere a Talcapillán, y además de reproducir en gran parte la carta anua de 1631, su relato aporta el motivo del cacique: fue a Chiloé a encontrarse con los jesuitas "por la fama de lo que los padres habían obrado en aquellas tierras" (Olivares 1874 [1736]:377).

La conclusión de los misioneros fue que "por medio de este indio se ha de abrir una nueva puerta al santo evangelio, siendo el precursor que lleve la buena nueva de él a una nueva gente que habita el estrecho de Magallanes, donde se conocen muchos bárbaros que no han oído el nombre santo de Cristo" (Sobrino 1631:64-64v). Talcapillán fue considerado, por lo tanto, una puerta a nuevos indígenas con el objetivo de la cristianización, y un nuevo grupo de quienes "servirse", por parte del gobierno político-militar. Sin embargo, la visita del jesuita al archipiélago de los Chonos y el encuentro con Ignacio Talcapillán, probablemente en 1631, fue el último intento misional hacia la Patagonia Occidental: en una carta de 1639 el misionero Juan del Pozo habla del archipiélago de los Chonos como un lugar al que se iba en el pasado (Ovalle 1642:78).

Los dos Delco e Ignacio Talcapillán cubren las primeras décadas del siglo XVII: 1609-1631. Los documentos no consignan la eventual información geográfica y etnográfica que pudieron haber dado a los jesuitas, o a García Tao. Lo único que se escribe es que hay grupos distintos a ellos hacia el confín de la tierra. Aun así, estos tres casos revelan las primeras tres relaciones interétnicas entre chonos y españoles, y muestran el proceso de aculturación de los primeros.

\section{Cristóbal Talcapillán y su Mapa, 1674}

Por sospechar el rey de España que Inglaterra planeaba establecerse en algún punto de la costa patagónica occidental, en 1673 el gobernador de 
Chile ordenó la vigilancia hasta el extremo austral. Desde Chiloé, su gobernador envió a un sargento mayor al reconocimiento. Jerónimo Díaz de Mendoza fue a comienzos de 1674, no halló lo buscado, y los indígenas australes no refirieron ninguna novedad. Sin embargo, llevó a Chiloé a algunos individuos denominados chonos.

La documentación va revelando cómo uno de ellos, Talcapillán, cuya edad se estimó en 25 años, se fue desenvolviendo en el mundo español. El gobernador los había dejado en el fuerte de Chacao, y al cabo de un par de meses Talcapillán "aprendió a hablar la lengua de los indios naturales de esta provincia", es decir, mapuche-veliche. En algún momento antes de junio de 1674, estando de visita en la casa de una mujer, le dijo que cerca de las tierras que él habitaba había dos poblados de "moros", es decir, extranjeros. Ella reportó esto a las autoridades del fuerte, quienes interrogaron formalmente a Talcapillán y escucharon de él el relato "y lo que no podía especificar por entonces, por no estar muy capaz en la lengua de los indios de esta provincia, lo pintaba en el suelo, y otras veces se daba a entender por semejanzas" (Gallardo, F. 29 de octubre de 1674).

Lo que contaba Talcapillán no podía dejar indiferente al gobernador insular, Francisco Gallardo, a cuyo cargo estaba la vigilancia de las costas australes, sobre todo ante la alarma causada por la llegada del inglés Narborough en 1670 al Pacífico, y las "noticias ciertas" de llegar ingleses nuevamente. Gallardo llevó a Talcapillán a Castro, y allí lo interrogó de manera tal que pudiera hablar en su propia lengua, sirviendo de intérprete un chono que -se escribió- hacía más de veinte años servía a un capitán de Chiloé, y por lo tanto hablaba las lenguas chona, española y veliche. Dada la gravedad del asunto, el interrogatorio fue delante "del cabildo y regimiento de la ciudad de Castro", de religiosos franciscanos y jesuitas, curas seculares, un licenciado, un capitán y otras personas de autoridad. En la ocasión se tomaron declaraciones a los chonos "apresados" por Díaz de Mendoza, además de Talcapillán: estos eran Jerónimo (su padre, bautizado por jesuitas hacía muchos años), Bartolo Caitalva, y una mujer.

Talcapillán dijo haber estado en una de las poblaciones de "moros", dando a entender que eran de ingleses, llamada Callanac, donde sus habitantes estaban construyendo una fortificación con la ayuda de indígenas, y dio una completa descripción de ella: estaba poblada por familias, había alianzas con unos grupos y guerras con los puelches que bajaban de la cordillera. Un indígena de Callanac, llamado León, había ido y vuelto de la tierra de los moros (Inglaterra), lo que supo Talcapillán por un amigo de ambos, Bartolo, antiguamente bautizado por un fiscal. La otra población estaba en una isla llamada Allauta, de la que también dio detalles. También sabía de un barco español naufragado en una isla de las que poseían los "moros", llamada Lluctui.

Hay muchos asuntos llamativos de Talcapillán, pero quizá el más significativo es su destacada capacidad de comunicar a otros el mundo al que pertenece, por medio de mapas. Talcapillán, para ilustrar el lugar donde estaban las colonias extranjeras, y lo lejos que habían estado de ellas las expediciones anteriores de reconocimientos australes (Rodrigo Navarro 1641 y Díaz de Mendoza 1674). Cada vez que lo refería dibujaba mapas que contemplaban tierras y mares. Él -se escribió- "pinta en el suelo y paredes su tierra e islambres de ella, con distinción de las que goza el enemigo y sus fortificaciones, las derrotas que han llevado los nuestros en diversas ocasiones y lo errado que anduvieron para llegar a las partes que hoy dice tiene el enemigo por suyas" (Gallardo, F. 29 de octubre de 1674). Los sobrevivientes de la expedición de Navarro de 1641 fueron llamados a observar el mapa y confirmaron que la información ilustrada por Talcapillán era "puntualmente" cierta. Gallardo hizo que Talcapillán dibujara su famoso mapa, esta vez en papel y con carboncillo, lo que hizo delante de todos en el interrogatorio. Un español iba rotulando en el mapa los nombres que él daba de parajes e islas. Ya rotulado, con un puntero se fueron indicando lugares y Talcapillán iba diciendo los nombres, coincidiendo con lo que había escrito. Como esto constó en la declaración por escrito, podemos saber qué hitos principales tenía el mapa. Estos eran isla Guaiteca; punta Guapasto; punta y río Caucagues; tierra de Pucaqui; isla tierra de Puelches, con un río por donde los puelches bajan de la cordillera; tierra donde los ingleses tienen centinela; tierra firme de Callanac, donde estaba la colonia; isla de Allauta, otra población inglesa ("Declaraciones de indios chonos", 7 de marzo de 1675). Esto terminó por darle credibilidad, porque Gallardo, sorprendido, reflexionaba que "causaba admiración ver que un indio bárbaro tuviese habilidad para hacer tal mapa" 
(Gallardo, F. 29 de octubre de 1674). Este mapa se traspasó, original, desde el gobernador de Chiloé, al de Chile, luego al virrey del Perú, y por último fue enviado al rey. ¿Qué lamentable que se haya perdido! ¿cómo habrá, un chono, representado su territorio?, ¿qué orientación cardinal le habrá dado al mapa?, ¿cómo habrá graficado las proporciones? ¿habrá Talcapillán visto mapas españoles en el fuerte de Chacao? ¡qué documento más exquisito!

El relato cobró mayor verosimilitud. El gobernador dispuso una expedición para recoger más información, con Talcapillán como guía. Envió como comandante a su hijo, Bartolomé Gallardo, con 30 infantes españoles y 40 "indios amigos", embarcados todos en siete "piraguas", lo que se ejecutó entre el 16 de octubre de 1674, y fines de enero de 1675 (Gallardo, B. 1886). Sin dar referencias en latitudes, se sabe que cruzaron la península de Taitao navegando por una laguna, y que desarmando las embarcaciones llegaron al golfo de Penas, pero no sabemos cuánto más avanzaron. Este cruce, que salvaba el obstáculo de doblar la península de Tres Montes, debe haber sido indicado por el guía Talcapillán, porque los relatos de expediciones hasta entonces no lo nombraban, a excepción del viaje de García Tao con Pedro Delco, en 1620. Hasta aquí, lo que Talcapillán contaba generó informes dirigidos al presidente de Chile y al virrey; una expedición de gran envergadura; y una provincia pendiente de lo que decía y dibujaba Talcapillán y los otros apresados.

El resultado de la expedición fue regresar con Felipe Baltasico y Luis Ninequema, "naturales de la provincia de Pucaqui", que confirmaban lo dicho por Talcapillán, quienes fueron llevados hasta Concepción para declarar ante el gobernador del reino, Juan Henríquez, sobre "la población que los ingleses tienen hecha de esta parte del estrecho de Magallanes" ("Declaraciones de indios chonos", 7 de marzo de 1675), lo que tuvo lugar el 25 y 28 de febrero, y 1 de marzo de 1675. A Talcapillán, con su mapa en frente, se le hizo nombrar los topónimos escritos en él para re-confirmar que no fuese un invento. La traducción se hizo por medio de dos chonos "inteligentes en la lengua de Chile", Juan Aguaco y Juan Mayles, que deben haber viajado desde Chiloé; desde el mapuche al castellano, la traducción fue hecha por un jesuita y un militar. Talcapillán explicó con detalle el tamaño de ambas poblaciones inglesas, describió sus murallas, baterías, la manera de vestir de las personas, una descripción física de ambos gobernadores, y otros hechos. Por lo anterior, el presidente envió a Talcapillán, Ninequema y Baltasico ante el virrey, pero este último murió en el trayecto a Lima. El virrey nombró a un oidor para la toma de declaraciones, en abril de 1675, y dispuso que sirvieran de intérpretes dos jesuitas conocedores "de la lengua general de los indios de Chile", y a uno de los dos Juan, hablante de chono y mapuche-veliche ("Declaraciones de Don Cristóbal Talquipillán y Luis Niquema", Lima, abril de 1675). En consecuencia, el virrey dispuso una nueva expedición, que fue la de los capitanes Antonio de Vea y Pascual de Iriarte, con 256 hombres en total, ejecutada entre septiembre de 1675 y abril de 1676, ida y vuelta desde el Callao, organizada "no perdonando gasto a la importancia de negocio de tan grave consecuencia en la magnificencia de su grandeza" (Vea 1675:578v). Ya encontrándose el grupo en los parajes donde estarían los ingleses, a Talcapillán, a bordo del barco de Vea, se le vio titubear. El intérprete dijo: "señor, dice [Talcapillán] que este general [Vea] va de veras, y que él quería decir la verdad" (Vea 1675:605). Se le preguntó "por qué nos había traído engañados", y dijo, "que por miedo del general Gallardo, y su hijo. Y preguntando, que porqué tenía este miedo, que si le habían inducido a que dijese estas cosas. Dijo, que le preguntaba que si había visto navíos, y que dijo que sí, y que si había visto molinos, que también, y pueblos, que sí, y que si había visto vino como aquel que le daban a beber, que también. Y que pintase las poblaciones, que lo hizo con su caletre, que con este mismo término lo dijo el intérprete, y que todo esto lo había dicho porque le parecía que gustaban los españoles de esto, y que nunca creyó que llegásemos tan adelante" (Vea 1675:606). Desengañados los españoles, ese fue el fin de la búsqueda.

Talcapillán fue considerado excepcional: destacaba por parecerle importante comunicar lo que comunicó (capacidad de comprensión del contexto español u "occidental"); por graficar mediante un mapa un territorio archipielágico de por sí difícil de representar, y derroteros; y por su locuacidad, desplante y capacidad de convencer. Causaba "admiración", dijo el gobernador Gallardo, la "habilidad" de este, "siendo bárbaro". Comparando, el virrey consideró que Ninequema "era menos capaz" que Cristóbal ("Declaraciones de Don Cristóbal Talquipillán y Luis Niquema", Lima, abril de 1675). Sus declaraciones tuvieron como consecuencia la 
expedición de Gallardo desde Chiloé; la atención especial del gobernador de Chile; su viaje al Perú junto a otros dos chonos; sus declaraciones en la audiencia virreinal; y la ejecución de la expedición más grande, hasta entonces, vista en Chiloé, que comprometió muchos recursos, y además causó la muerte de 16 hombres, entre ellos un hijo de Iriarte, en la latitud $52^{\circ}$ y medio aproximadamente. Su relato de los ingleses o Césares fue conocido en toda América: dice el virrey del Perú, "he participado las de estas poblaciones al presidente de Panamá, corregidores y gobernadores de todas estas costas del Perú y de la Guatemala, el Realengo, Sonsonate y Nueva España en conformidad de lo resuelto en el acuerdo, para que en todas partes se esté en la vigilancia, resguardo y prevención que pide la gravedad del negocio, que no duda es de la mayor que se puede ofrecer" (El virrey del Perú al rey, 28 de abril de 1675).

Cristóbal Talcapillán, aun cuando no había interactuado con los españoles de Chiloé antes del episodio señalado, las fuentes lo muestran más aculturado que los Delco e Ignacio: convive con individuos que habían sido bautizados, y sabe que los españoles de Chiloé consideran unos "no indios" como otros y enemigos (los moros). Además, aprendió la lengua indígena de Chiloé, supo hacer representaciones visuales inteligibles a los españoles y espacializó en ella hitos y derroteros.

\section{Martín Olleta y los Náufragos Ingleses, 1742}

En mayo de 1741 encalló el barco inglés Wager en una de las islas del archipiélago de Guayaneco. Tripulado por 150 personas, formaba parte de una flota de siete barcos, comandada por George Anson, que pasó el cabo de Hornos con el objetivo de asediar poblaciones españolas en el Pacífico (Williams 2002). Entre deserciones y huidas en las embarcaciones auxiliares, y muertes por agotamiento y hambre, solo 13 hombres se encontraban en el lugar del naufragio un año más tarde, cuando un grupo de indígenas, liderado por uno que dijo llamarse Martín, llegó hasta aquel lugar, alertado de la novedad por otros indígenas. Era común que grupos distintos se encontraran en explotaciones de naufragios en esas costas. Otros indígenas habían visitado a los ingleses, pero este, Martín, era diferente. John Byron, a posteriori, lo identificó como "de la tribu de los chonos, que habita en la vecindad de Chiloé" (Byron 1975:79); daba importancia al hierro; se distinguía de los demás por hablar algo de español; tenía un nombre cristiano; y era el cabecilla del grupo. Los ingleses interpretaron que era un cacique, debido a la autoridad que demostraba y el portar el reconocible distintivo de aquello: bastón con empuñadura de plata. Mantenía contacto con los españoles de Chiloé, y por eso, finalmente, fue quien los condujo.

Martín llegó al naufragio interesado en el metal que tenían los ingleses en el campamento, y el que estaba en el precio. Con el grupo que lideraba lo recolectó, acumuló, y transportó parte de él a Chiloé en sus dalcas cuando llevó a los náufragos. Al llegar a algún punto en el sur de la isla grande, lo escondió para que no le fuese confiscado (Byron 1955:48), lo que da cuenta de conocer el valor que los españoles de Chiloé le daban, del que era muy escasa la provincia, y sobre la manera en que los chonos u otros grupos lo intercambiaban. Además, sabía que estos náufragos eran distintos a los españoles, y que dar la noticia de su existencia en Chiloé iba a ser valorado. El rector del colegio jesuita de Castro lo dice así: "porque el ir los indios chonos a Guayaneco les es y ha sido siempre lícito, porque aunque no son tierras suyas, son confinantes a las suyas, y siempre se han comunicado estos indios con aquellos, como que son indios todos, aunque de distintos idiomas, y siempre han andado revueltos. Y por esta comunicación y amistad el cacique don Martín Olleta topó en aquellos remotos parajes y halló a los ingleses náufragos, y trajo a esta provincia, mérito que se le ha quedado sin remuneración" (Pedro García, 7 de mayo de 1744:20). Así, la comunicación entre Martín, que frecuentaba Chiloé, e indígenas que frecuentaban el área de Guayaneco y golfo de Penas, permitieron que este supiese sacar provecho de los ingleses y el metal. Además, salvó la vida a cuatro oficiales británicos. Los enfermos y famélicos náufragos iniciaron con Martín un lento viaje, tan trabajoso que algunos huyeron para no soportar más fatigas. Alcanzaron la costa norte del golfo de Penas y se internaron por un río avanzando luego por tierra con las dalcas desarmadas, para coserlas en la orilla de la península de Taitao, continuando por mar. Esta ruta indígena evitó remontar la barrera que significa el golfo de Penas, así como también lo hizo Bartolomé Gallardo en 1674, pero en sentido norte-sur, en una ruta similar en la misma península de Taitao. Con este viaje, Martín reveló a los españoles una ruta que fue utilizada en los viajes posteriores al lugar 
del naufragio (Urbina 2010). En Chiloé entregó los ingleses a las autoridades. Los náufragos hicieron saber del extravío que sufrió el teniente Hamilton en el periplo, y el gobernador dispuso que Olleta se volviera a buscarlo. El hallarlo en el laberinto de aquellas islas evidencia la experticia de los chonos en ellas, y la comunicación entre quienes las habitaban y frecuentaban. A esto debe haberse referido Walter Hanisch en su elocuente frase sobre los canoeros australes: "lleva el mapa en la mente" (Hanisch 1982:88).

En el Archivo del Arzobispado de Santiago de Chile existe un expediente sobre un conflicto entre el gobernador de Chiloé y el colegio jesuita de Castro, en 1744, con valiosa información sobre chonos y un grupo llamado caucahués (Urbina 2015). Por él sabemos que para ese año Martín era apellidado Olleta, "gobernadorcillo de dicha nación chonos, morador de la isla de Cailín" (Martínez de Tineo, 14 de marzo de 1744:2), y suponemos que el morar en Cailín es consecuencia de su actuación pasada, porque su revelación hizo que los españoles fueran a buscar metal al naufragio, y los jesuitas a recolectar y trasladar a los nuevos "gentiles" dados a conocer por los ingleses, y estos últimos fueron acomodados en Cailín desde 1743. Así se advierte cuando en 1744 se hizo matrícula de los "guaiguenes" (otro grupo que nomina el expediente citado) -dice el gobernador- que residen en Cailín, "donde habita el gobernadorcillo de todos los expresados indios": había 50 personas, "y es de advertir que en este dicho número se comprenden los que viven en las islas más remotas, según lo declara su gobernador don Martín Olleta, donde solo ellos transitan, como es Guapiquilan, Quilán y otras islas, de suerte que son por todos 132" ("Tenientes de la real hacienda al gobernador", 27 de marzo de 1744).

La revelación de Olleta tuvo significativas consecuencias: salvó la vida de cuatro ingleses; comprobó a las autoridades de Chiloé que no podían instalarse enemigos en la Patagonia Occidental sin enterarse de ello; dio a conocer "nuevos" indígenas -caucahués-que entusiasmaron a los jesuitas (lo que en 1764 dio origen a la fundación de una misión en la isla Cailín); enseñó una ruta indígena para obviar el golfo de Penas y poder acceder a Guayaneco; y Olleta comenzó a ejercer de vínculo efectivo entre las autoridades de Chiloé y grupos indígenas australes, como puede verse en el expediente citado. Martín Olleta, como Talcapillán, conocía a los "moros", pero además, y a diferencia de los anteriores individuos aquí tratados (de acuerdo con lo que consignan los documentos), sabe del valor del hierro y se relaciona con otros grupos (caucahués).

\section{Conclusiones}

En Chiloé colonial, la forma de controlar su vasta frontera sur no fue mediante la ocupación efectiva y presencia permanente, sino que las autoridades de Chiloé se proyectaban hacia ella por medio de navegaciones de reconocimiento, viajes misionales, y principalmente, la información conseguida de los indígenas. Lo que se buscaba saber era la existencia de náufragos españoles (preferentemente en el siglo XVII), de ingleses, o de indígenas no contactados antes.

De los grupos llamados canoeros australes el chono era el que con mayor frecuencia e intensidad entró en contacto con los habitantes de Chiloé durante el período colonial, por ser el más próximo. Determinados líderes tuvieron contacto durante meses o años con las autoridades de Chiloé, interesados estos, quizá, por elementos materiales de la cultura que en la isla grande se asentaba, como Pedro y Francisco Delco, e Ignacio Talcapillán. Los españoles les dieron tratamiento de "Don" (al menos en la documentación) y los identificaron por sus nombres -a los que antepusieron los recibidos del bautismo- repitiéndose los de Delco y Talcapillán. Muestran las fuentes que no se trata de apellidos traspasados de padre a hijo, sino al parecer, dan cuenta de una especie de patronímicos asignados por los españoles.

Los de Chiloé supieron atraer el interés de estos líderes, reconociéndolos como caciques y dándoles objetos distintivos que pudieran ser de su agrado, lo que era una práctica común en otros lugares de frontera, para atraer a caciques lejanos mediante "agasajos" con el fin de tener "amistamientos". Los dos Delco e Ignacio Talcapillán, según muestran las fuentes, voluntariamente se acercaron a Chiloé y mantuvieron relación con los misioneros jesuitas. En esto hay que ver, además de una natural curiosidad, la búsqueda de paz y protección frente a las capturas de individuos de su grupo que los de Chiloé habían hecho en las primeras décadas del siglo XVII. Ya en 1674, Cristóbal Talcapillán no buscó a los de Chiloé, sino que al contrario, lo fueron a buscar. Trasladado a Chacao, aprendió la lengua de los indígenas de la isla grande, y pudo comprender parte del mundo español, lo suficiente como para 
agradarles diciéndoles lo que ellos querían escuchar. Martín Olleta, por su parte, sabía bien qué era lo que agradaba a los españoles de Chiloé y supo valorar las noticias que viajando de isla en isla llegaron a él: a las autoridades les interesaban los extranjeros; a la población en general el metal; y a los jesuitas los indígenas "nuevos".

La relación con estos cinco chonos no parece ser permanente, ni hereditaria, y desde la perspectiva española no estuvo institucionalizada ni constituyó formal alianza. Tampoco podría haberlo sido, debido a su movilidad y a la disgregación y dispersión en la que vivían. Por medio de regalos, y probablemente juramentos y reiterados actos de toma de posesión, los españoles de Chiloé valoraron estos contactos, que dadas las circunstancias, era lo mejor con lo que se podía contar como forma de conocimiento. Españoles e indígenas eran conscientes de la ventaja que llevaban los segundos, al poder optar a no volver a Chiloé, por "ser fuertes en sus islas". En todos los casos (excepto el de Cristóbal Talcapillán, por habérsele desarraigado de su territorio), los jesuitas fueron un instrumento para reafirmar el vínculo con indígenas que, como en otros lugares de fronteras de América colonial, no estaban efectivamente incorporados al sistema colonizador castellano.

El objetivo de los jesuitas era evangelizar a todas las "naciones" de indios que, pensaban, se sucedían hasta el estrecho de Magallanes; el de las autoridades políticas de Chiloé era la vigilancia o patrullaje, a través de ellos, del complejo panorama geográfico y étnico del territorio patagónico occidental, cuyos millares de islas multiplican la extensión de las costas. Los chonos con que interactuaron, en rigor, mediadores culturales, en las fuentes españolas se muestran como voluntarios y ocasionales, pero un medio efectivo para conocer al menos parcialmente un inmenso territorio vedado a los españoles por sus características geográficas. Sus noticias son en realidad respuestas, actitudes reactivas ante la alteración provocada por los españoles, y fueron útiles para que estos últimos se formasen una representación de aquel territorio. Ofrecen los caciques chonos, principalmente, las denominaciones de grupos distintos a ellos (huillis-caucahués); el espacio físico donde se ubican los otros (hacia el sur de ellos); si tienen o no hostilidades entre sí (Pedro Delco y Cristóbal Talcapillán); y alguna otra diferenciación. Fueron informaciones eficaces, porque el gobernador de Chiloé -sobre todo en el siglo XVIII, cuando hubo varios episodios de guerra entre España e Inglaterra y se sospechaba querer los segundos apoderarse de alguna isla en la Patagonia-contaba con los chonos que frecuentaban las Guaitecas o algunas islas del mar interior de Chiloé, como Cailín y Chaulinec, para averiguar las posibles alteraciones en ese mundo. Por ejemplo, preguntado en 1767 el ex gobernador insular Antonio de Santa María, sobre la frontera sur, aseguró que "en aquel archipiélago [de los Chonos] no se debía solicitar mayor conocimiento que el que se tiene" ("Parecer de la Contaduría sobre la fundación de Chonchi y misión de Cailín", Madrid, 28 de febrero de 1767).

En los cinco casos expuestos, los chonos fueron revelando un mundo austral bordemarino, y sus derroteros, lo que era la antítesis del mundo español, de hitos terrestres. Para los españoles carecía de nominaciones (excepto las que dio Delco a García Tao y las señaladas por Cristóbal Talcapillán), ni contenía más referentes geográficos que el estrecho de Magallanes (excepto Cristóbal) que ya formaba parte de la representación geográfica, parecían brumosas soledades. Destaca, con mucho, Cristóbal Talcapillán, que dibujaba mapas para representar gráficamente hitos de su geografía real que los españoles podrían significar como relevantes. Todos ellos fueron comunicando información geográfica y de las poblaciones que habitaban aquellos territorios, aunque muy escueta, lo que fue constituyendo un corpus de conocimiento del espacio patagónico insular utilizado para los intereses de los españoles de Chiloé, pero a partir del conocimiento indígena (De Lasa y Luiz 2011). Además de ser agentes de información, estos mismos caciques chonos sirvieron de guías o pilotos en las navegaciones españolas, y de vínculo entre españoles y grupos aún no contactados. En este asunto de las comunicaciones, es importante destacar el aprendizaje de la lengua mapuche-veliche de Pedro Delco y Cristóbal Talcapillán, y los rudimentos de español de Martín Olleta; el papel de chonos que vivían en Chiloé y que tradujeron del chono al mapuche-veliche, y el de los jesuitas como intérpretes de este al castellano, en Chiloé, Chile y Lima.

Conocer a estos chonos es aproximarnos también al proceso de aculturación de este grupo. Desde Pedro Delco, quien desde antes de 1609 comerciaba con los indígenas de la isla grande, hasta Martín Olleta, "gobernadorcillo" (ya no solamente cacique) de un grupo trasladado a Cailín y que hablaba algo de castellano, en 1742. En la práctica ellos fueron mediadores entre la cultura española y la propia, y 
entre esta y la de otros grupos de lenguas diferentes (como los caucahués) con quienes se comenzó a interrelacionar España tardíamente, y gracias a la revelación y vínculo de Martín Olleta. Es también aproximarnos a la comprensión que las autoridades políticas y espirituales tenían sobre el confín austral, en un lapso de 150 años, cuando el desconocimiento territorial y poblacional comenzaba desde la boca del Guafo hacia el sur, en 1609, hasta mediados del siglo XVIII, cuando se había adaptado la dalca como herramienta para transitar los archipiélagos de los Chonos y Guayaneco, y se utilizaban rutas indígenas hacia el sur a través de la península de Taitao.

Agradecimientos: Este artículo es fruto del Proyecto Interno Regular 2014, N 37.390, Pontificia Universidad Católica de Valparaíso. Agradezco también a quienes han sido evaluadores de este artículo, por sus enriquecedores comentarios.

\section{Referencias Citadas}

\section{Fuentes no impresas}

AA. VV. 1927. Cartas Anuas de las Provincias de Paraguay, Chile y Tucumán de la Compañía de Jesús: 1609-1614, Documentos para la Historia Argentina, T. XIX. Talleres S.A. Casa Jacobo Peuser Ltda., Buenos Aires. Carta Anua de 1609. Diego de Torres, Córdoba, 17 de mayo de 1609, p. 22; de 1610, 5 de mayo de 1611, pp. 110-112; de 1613, Córdoba, 8 de mayo de 1614, pp. 380-384.

"Adiciones a la carta anua de 1611", Archivun Romano Societatis Iesu (ARSI), Roma, Provincia de Paraguay, Vol. 8.

"Cartas Anuas de la provincia del Paraguay de los años 1618 y de 1619”, Córdoba, 7 de febrero de 1620, ARSI, Paraguay, Vol. 8.

"Carta del virrey del Perú al rey dando cuenta de las noticias que ha tenido de estar poblados los enemigos de Europa al sur de Chiloé", Lima, 28 de abril de 1675. Archivo General de Indias de Sevilla (AGI), Audiencia de Chile, 23, R.3, N. 83.

"Declaraciones de indios chonos ante el gobernador de Chile", Concepción, 7 de marzo de 1675. AGI, Chile, 7.

"Declaraciones de Don Cristóbal Talquipillán y Luis Niquema en Lima ante su excelentísima, indios chonos remitidos por el gobernador de Chiloé, sobre las poblaciones de los ingleses, que son los mismos que declararon en la Concepción, y el primero lo hizo también en Chacao ante el gobernador de Chiloé, el cual es el autor y primer instrumentos de estas noticias", Lima, abril de 1675. AGI, Chile, 23, R.3, N.83.

"Gallardo, F., gobernador de Chiloé, al presidente de Chile", Chacao, 29 de octubre de 1674. AGI, Chile, 7.

"García, P., rector del colegio jesuita de Castro, al gobernador de Chiloé", 7 de mayo de 1744. AAS, Expediente s/c, fjs. 17-22.

García Tao, J., "Relación del viaje que hizo Juan García Tao a fines de 1620 en busca de las poblaciones fabuladas denominadas Césares, saliendo de Chiloé y siguiendo por mar y en débiles piraguas al reconocimiento de la costa del sur hacia el estrecho de Magallanes". Archivo Nacional Histórico de Santiago (ANH), Fondo Vidal Gormaz, Vol. 9, pza 16.

"Martínez de Tineo, gobernador de Chiloé, al presidente de Chile", Chacao, 14 de marzo de 1744, fjs. 2-2v. Archivo Arzobispal de Santiago (AAS), Expediente sin clasificación (s/c).

Ovalle, A. "Memorial y carta en que el padre Alonso de Ovalle, procurador general de la Provincia de Chile, representa a N.
Muy Reverendo Padre Mucio Vitilesqui, prepósito general de la Compañía de Jesús, la necesidad que sus misiones tienen de sujetos para los gloriosos empleos de sus apostólicos misioneros", Sevilla, 12 de marzo de 1642. ARSI, Provincia de Chile, Vol. 4. Esta carta contiene una del jesuita Juan del Pozo.

"Parecer de la Contaduría sobre la fundación de Chonchi y misión de Cailín”, Madrid, 28 de febrero de 1767. AGI, Chile, 240.

Sobrino, G. "Letras anuas de esta provincia de Chile de los años 1629 y 30", Santiago, 2 de marzo de 1631. ARSI, Chile, Vol. 6, fjs. 63v-64v.

"Tenientes de la real hacienda al gobernador de Chiloé", Chacao, 27 de mayo de 1744. AAS, Expediente s/c, f. 41v.

Vea, A. "Relación diaria del viaje que se ha hecho a las costas del estrecho de Magallanes, en el recelo de enemigos de Europa, por Don Antonio de Vea". Archivo del Museo Naval de Madrid (AMNM), Colección Fernández Navarrete, T. XX, Ms. 199, fjs. 576-619.

\section{Fuentes impresas}

Álvarez, R. 2002. Reflexiones en torno a las identidades de las poblaciones canoeras situadas entre $\operatorname{los} 44^{\circ}$ y $48^{\circ}$ de latitud Sur, denominadas 'Chonos'. Anales del Instituto de la Patagonia, Serie Ciencias Humanas 30:79-86.

Byron, J. 1955. El Naufragio de la Fragata Wager. Zig-Zag, Santiago.

Chartier, R. 1992. El Mundo como Representación. Historia Cultural. Entre Práctica y Representación. Gedisa, Barcelona.

De Lasa, L y M. Luiz 2011. Representaciones del espacio patagónico. Una interpretación de la cartografía jesuítica de los siglos XVII y XVIII. Cuadernos de Historia 35:7-33.

Gallardo, B. 1886. Relación del sargento mayor Don Bartolomé Gallardo hecha en Lima de orden de V. E. sobre el viaje que hizo en reconocimiento a las poblaciones de los ingleses con todo lo sucedido en él y paraje donde llegó. Anuario Hidrográfico de la Marina de Chile 9:525-537.

García, J. 1811. Diario del viaje y navegación hecho por el padre Joseph García de la Compañía de Jesús desde su misión de Kaylin en Chiloé hacia el sur. Año 1766. En Nachrichten von erschiedenen Landern des Spanischen Amerika, editado por C. Gottlieb von Murr, pp. 506-598. Verlegt bev Joh. Christian Hendel, Halle. 
Hanisch, W. 1982. La Isla de Chiloé, Capitana de Rutas Australes. Academia Superior de Ciencias Pedagógicas de Santiago, Santiago.

Lira, N. y D. Legoupil 2014. Navegantes del sur y las regiones australes. En Mar de Chile, editado por C. Aldunate, pp. 103143. Museo Chileno de Arte Precolombino, Banco Santander, Santiago.

Mena, F. 1985. Presencia indígena en el litoral de Aisén. Trapananda 5:203-213.

Olivares, M. 1874. Historia de la Compañía de Jesús en Chile (1593-1736). Colección de historiadores de Chile y de documentos relativos a la Historia Nacional, T. VII. Imprenta Andrés Bello, Santiago.

Quiroz, D. y J. Olivares 1988. Nómades canoeros de la Patagonia septentrional Insular: el mundo de don Pedro del Agua. En Encuentro de Etnohistoriadores, editado por O. Silva, E. Medina y E. Téllez, pp. 10-33. Serie Nuevo Mundo. Cinco Siglos, Departamento de Ciencias Históricas, Universidad de Chile, Santiago.

Reyes, O., M. Moraga, C. Méndez y A. Cherkinsky 2015. Maritime hunter-gatherers in the chonos archipelago (43 $50^{\circ}$ $46^{\circ} 50^{\prime} \mathrm{S}$ ) western patagonian channels. Journal of Island \& Coastal Archaeology 10:1-25.

Rosales, D. 1991. Seis misioneros en la frontera mapuche (Del Libro IV de la Conquista Espiritual del Reino de Chile, Volumen I, de Diego de Rosales). Introducción, Traducción y Notas de Gustavo Valdés Bunster, Centro Ecuménico Diego de Medellín, Universidad de la Frontera, Temuco.
Todorov, T. 1987. La Conquista de América: el Problema del Otro. Siglo XXI, Ciudad de México.

Urbina, R. 2007. El pueblo chono: de vagabundo y pagano alzado a cristiano y sedentario amestizado. En Orbis Incognitus. Avisos y Legajos en el Nuevo Mundo. Homenaje al Profesor Luis Navarro García, editado por F. Navarro. Tomo I, pp. 325-346. Ediciones de la Universidad de Huelva, Huelva.

Urbina, R. 2012 [1983]. La Periferia Meridional Indiana. Chiloé en el siglo XVIII. Ediciones de la Pontificia Universidad Católica de Valparaíso, Valparaíso.

Urbina, X. 2010. La navegación por los canales australes en la Patagonia occidental insular en los siglos coloniales: la ruta del istmo de Ofqui. Magallania 38:41-67.

Urbina, X. 2013. Expediciones a las costas de la Patagonia occidental en el período colonial. Magallania 41:51-84.

Urbina, X. 2014. Fuentes para la Historia de la Patagonia Occidental en el Período Colonial. Primera parte, Siglos XVI y XVII. Ediciones de la Pontificia Universidad Católica de Valparaíso, Valparaíso.

Urbina, X. 2015. "El naufragio de la Wager en el Pacífico austral y el conflicto del hierro en Chiloé". En Del Mar de Sur al Pacífico, editado por R. Sagredo y R. Moreno, pp. 241-280. Editorial Universitaria-DIBAM, Santiago, en prensa.

Vázquez de Acuña, I. 1993. La jurisdicción de Chiloé (siglos XVI al XX). Su extensión, exploración y dominio. Boletín de la Academia Chilena de la Historia 103:111-191.

Williams, G. 2002. El Mejor Botín de Todos los Océanos. La Captura de la Nao de China en el Siglo XVIII, Editorial Océano, Ciudad de México. 